\title{
Quando o capitalismo transforma o espaço urbano em mercadoria: 0 direito à cidade na Vila Autódromo/RJ frente à agenda neoliberal de megaeventos esportivos
}

\author{
When capitalism transforms the urban space in merchandise: \\ the right to the city in Vila Autódromo/RJ in front of \\ neoliberal agenda of mega sporting events
}

\author{
Vitor Fraga da Cunha \\ Eleonora Freire Bourdette Ferreira
}

\begin{abstract}
Resumo
O direito à moradia é um direito social, ele abrange a segurança legal da posse, a disponibilidade de serviços, materiais e infraestrutura, o custo acessível, a habitabilidade, a acessibilidade, localização e adequação cultural, em uma vertente associada ao ideário de direito à cidade. Então, é possível perceber que não há dignidade humana sem moradia. Mas a questão habitacional é um problema sócio-histórico brasileiro, porque apesar do direito à moradia está positivado na Constituição, muitas pessoas não possuem moradia adequada. Nesse contexto, este trabalho discutirá a distância entre o direito e a realidade. Escolheu-se a conjuntura da cidade do Rio de Janeiro, cenário da principal reforma urbana realizada no Brasil nas últimas décadas, para adequar a segunda maior cidade do País às demandas dos megaventos esportivos internacionais - a Copa do Mundo em 2014 e os Jogos Olímpicos em 2016. O objetivo geral do trabalho é analisar o modelo de city-marketing implementado no Rio de Janeiro e o objetivo especifico é identificar os interesses e sujeitos envolvidos no processo de remoção da Vila Autódromo - localizada no Bairro da Tijuca/ $\mathrm{RJ}$, também pretende analisar se o direito constitucional à moradia e a dignidade humana foram concretizados na Vila. A metodologia escolhida tem orientação epistemológica da Teoria Crítica através do marco teórico-metodológico do materialismo histórico dialético, adotam-se ainda os raciocínios indutivo e dedutivo, numa pesquisa qualitativa, o que envolve revisão bibliográfica e análise documental como técnicas de pesquisa.
\end{abstract}

Palavras-chave: teoria crítica; direito à cidade; Rio de Janeiro; Vila Autódromo 


\begin{abstract}
The home right is a social right, it is related with legal security of tenure, availability of services, materials and infrastructure, affordable cost, habitability, accessibility, location and cultural appropriateness, in an area associated with the right to the city. So, it is possible to perceive there is not human dignity without home. But the question housing is a socio-historical brazilian problem, because although of home right is in Brazilian Constitution, many people do not have proper home. In this context, this paper aims to discuss the distance between law and reality. It was chosen the conjuncture of the city of Rio de Janeiro, which is the scene of main urban reform in Brazil in the last decades, to adapt the second biggest city of the country to the demands from the mega international sportive events - the World Cup in 2014 and the Olympic Games in 2016 The general objective this paper is to analyses the city-marketing model implemented in Rio de Janeiro and specific objective is to identify the interests and subjects involved in removal process of Vila Autódromo, localized in Bairro da Tijuca/RJ, also intends to analyse if the constitutional right to home and the principle of human dignity were concretized in the Vila. It is adopted the methodology of research with epistemological reference in the Critical Theory, through a theoretical and methodological guideline of the historical and dialectic materialism. It is used inductive and deductive reasoning, through the tools of qualitative research, which involve bibliographical review and documentary analysis as techniques of research.
\end{abstract}

Keywords: critical theory; right to the city; Rio de Janeiro; Vila Autódromo

\section{Introdução}

Os direitos sociais surgiram para suprir a lacuna formalista deixada pelos direitos de primeira geração - para os quais bastaria a inação do Estado. O que é evidentemente falso, afinal de contas o direito que mais depende de prestaçōes do Estado para subsistir é exatamente o direito de propriedade - liberal por excelência - com a defesa da prestação positiva do Estado por intermédio de serviços, organismos e políticas públicas. Entre os direitos sociais está o direito à moradia (art. 6 을 CF). Maria Rita Rodrigues (2016, p.56) explica que direito à moradia não compreende somente o direito de ter um abrigo, neste direito está incluso a segurança legal da posse, a disponibilidade de serviços, materiais e infraestrutura, o custo acessível, a habitabilidade, a acessibilidade, localização e adequação cultural, em uma vertente associada ao ideário de direito à cidade.

A efetivação deste direito integra o conteúdo de cidade social, fazendo com que a questão habitacional esteja inserida no complexo feixe de problemas urbanos, seja pela ausência de habi- tação, seja pela precariedade daquelas existentes, presentes em muitas cidades, exigindo a formulação e a implementação de políticas públicas adequadas. (BELLO; FERREIRA; DIAS, 2016, p.25).

Assim é possível perceber que não há como consagrar a dignidade humana - princípio basilar positivado na Constituição (art. 1ํ, III) - sem moradia. Contudo, a questão habitacional é um problema sócio-historico brasileiro. No Brasil, entre as décadas de 1940 e 1980, a população passou de predominantemente rural para majoritariamente urbana e hoje encontra-se no patamar de urbanização de $84 \%$, conforme o censo do IBGE de 2010. Esse aumento de população nas cidades ocorreu sem que o perímetro urbano tivesse estrutura e condiçōes de abrigar esses novos habitantes, assim os grandes problemas urbanísticos começaram a ganhar destaque, como a pobreza urbana: milhões de pessoas vivendo em condiçōes precárias em morros, alagados, várzeas.

Os dados estatísticos do IBGE, colhidos no ano de 2006 através da PNAD (Pesquisa Nacional por Amostra de Domicílios), indicam que havia 
no Brasil um déficit de 7.934 .719 moradias, número equivalente a $14,5 \%$ do total de domicílios do país (54.610.413). Na região metropolitana do Rio de Janeiro, o déficit habitacional montava, à época, em 457.839 unidades, o que correspondia a $11,7 \%$ dos domicílios ${ }^{1}$. No Censo de 2010, o IBGE identificou que o número de casas vazias $(6,07$ milhōes) superava o do déficit habitacional do país (5,8 milhões de moradias)².

Vale destacar: a habitação digna é uma das prioridades que a Uniāo definiu para a realização de programas e políticas de desenvolvimento urbano. O texto constitucional, em seu artigo 21, estabelece: "Compete à Uniāo: [...] XX - Instituir diretrizes para o desenvolvimento urbano, inclusive habitação, saneamento básico e transportes urbanos". Tal direito é tão elementar que a constituição brasileira (art. 23, XI) define como competência de todos os entes da Federação a promoção de programas de construção de moradias e de melhoria das condiçōes habitacionais e de saneamento básico. Além do Estatuto da Cidade determinar a competência do município para realizar o pleno desenvolvimento das funçōes sociais da cidade.

É possível constatar o descompasso entre a realidade e as leis, a positivação de um direito nesta não garante a sua efetivação naquela. É deste ponto que este trabalho parte, a positivação de algum direito em nosso ordenamento não é causa o suficiente para concretiza-lo na prática. Desta forma, uma pesquisa dogmática - abordagem clássica na área do Direito - se mostra insuficiente para a compreensão do problema. Que demanda uma abordagem que permita identificar as contradições e os obstáculos existentes para efetivação do direito à moradia. A complexidade da questão se perde se partirmos de análises dogmáticas, onde o direito é compreendido apenas como norma. Aqui, as questōes envolven- do a inaplicabilidade dos direitos humanos, bem como as soluçōes apresentadas, ficam restritas a discursos vazios e medidas meramente formais que se encerram dentro de um universo normativo, aparentemente fechado em si próprio, que não se comunica com o mundo real. É necessário, portanto, compreender o direito para além do discurso tradicional, a partir do concreto, da realidade, ou seja, dos significados que vão sendo atribuídos pelos setores da sociedade aos fatos e as normas, e que não se resumem ao direito positivado ou as jurisprudências dos tribunais.

Este trabalho tem por objetivo geral analisar o que é a "cidade-empresa" e como esse modelo vem sendo implantado na cidade do Rio de Janeiro, bem como delimitar as disputas empreendidas em torno do que seja direito à cidade e as tensões de classe pela efetivação desse direito. Este trabalho tem como objetivo especifico identificar os sujeitos sociais e interesses envolvidos no processo de remoção da Vila Autódromo, localizada no Bairro da Tijuca - RJ e também pretende analisar se o direito constitucional à moradia e a dignidade humana foram concretizados na Vila.

Como busco compreender o direito para além do universo normativo, a metodologia escolhida tem orientação epistemológica da Teoria Crítica através do marco teórico-metodológico do materialismo histórico dialético, essa escolha é justificada por a sociedade e as relações materiais que nela se estabelecem serem dialéticas e históricas, pois

Não há algo dado imediatamente por toda a eternidade, uma coisa sempre igual a si mesma, mas sim produto da indústria e do estado da sociedade; isto, na verdade, no sentido de que é um produto histórico, o resultado da atividade de toda a série de geraçōes, cada uma das quais alcançando-se aos ombros da precedente, desenvolvendo sua indústria e seu comércio, modificando

\footnotetext{
${ }^{1}$ INSTITUTO NACIONAL DE GEOGRAFIA E ESTATÍSTICA. Síntese de indicadores sociais de 2006. Brasília, 2006. Disponível na internet em: http://www.ibge. gov.br/home/estatistica/ populaçāo/ condicaodevida/indicadoresminimos/sinteseindicsociais2006/indic_sociais2006.pdf

${ }^{2}$ BRASIL Número de casas vazias supera déficit habitacional do país, indica Censo 2010. Brasília, 2010. Disponível na internet em: http://www.brasil.gov.br/
} noticias/arquivos/2010/12/13/numero-de-casas-vazias-superadeficit-habitacional-do-pais-indica-censo-2010. 
a ordem social de acordo com as necessidades alternadas. (MARX, 1986, p. 66).

Adotam-se ainda os raciocínios indutivo e dedutivo, numa pesquisa qualitativa, através das técnicas de pesquisa da revisão bibliográfica e análise documental.

Segundo Herrera Flores (2005), os marcos teóricos tradicionais se baseiam em uma racionalidade universalista, suspostamente neutra e descontextualizada, enquanto a teoria critica parti das práticas sociais existentes, com a intenção de se romper com as fundamentaçōes abstratas e gerais que na prática inviabilizam formas de ação alternativas, que poderiam construir outros caminhos, em prol da emancipação. Avalio que tal concepção se conjuga bem com o materialismo histórico e dialético, pois este se ocupa das relaçōes históricas concretas a que o campo diz respeito, com as suas contradiçōes. O pesquisador que adota o materialismo histórico dialético tem a tarefa de ser contemporâneo a si mesmo, isto é, assumir subjetivamente o momento histórico sem se deixar ofuscar pelos termos e temas do debate impostos pelos "vencedores" da história.

Ao partir do ponto em que não há neutralidade e que vivemos em um momento da história norteado por relaçōes sociais capitalistas, no qual há uma luta de classes, adotar o materialismo histórico é assumir um lado, no caso, o lado do proletariado. Esse método permite compreender que direitos nascem das relaçōes sociais, são construídos ao longo da história, então tais direitos podem ser modificados, anulados e interpretados. E ao assumir um lado, o pesquisador não deve só entender e descrever a realidade, deve buscar transforma-la, "trata-se de revolucionar o mundo existente, de atacar e transformar, praticamente, o estado de coisas que ele encontrou". (MARX, 1986, p. 66).

\section{0 Direito sob a luz da teoria crítica}

A fim de apresentar ao leitor um modo não habitual de tomar o direito, uma vez que tradicional- mente o direito é estudado de modo técnico-dogmático, esta primeira parte do trabalho é destinada a fazer uma breve explanação dos referencias teóricos-metodológicos no qual esta pesquisa é calcada, e a luz deles tecer uma crítica ao direito e teoria tradicionais.

A teoria critica analisa o mundo como ele é a partir das potencias que ele poderia ser, aponta para a prática como realização dessas potências. Para Horkheimer (1980), o que define o comportamento crítico é a consciência que possuem os sujeitos que as contradiçōes de seu mundo resultam da produção humana e histórica de sistemas que se relacionam mutuamente e que são impostos ao homem pelo próprio homem, numa determinada circunstância histórica

A transformação do todo, pode servir-se sem dúvida do trabalho teórico, tal como ocorre dentro da ordem desta realidade existente. Contudo, ele dispensa o caráter pragmático que advém do pensamento tradicional como um trabalho profissional socialmente útil. (HORKHEIMER, 1980, p. 131).

O trabalho socialmente útil citado por Horkheimer se refere ao fato do comportamento crítico se orientar para a mudança. Tendo consciência das categorias dominantes do processo social e tomando parte do processo de produção das contradições sociais, o sujeito crítico é definido como sujeito social que não se submete às determinaçōes impostas pelo sistema social, as quais são geralmente explicadas pela teoria tradicional como sendo naturais, de acordo com o modelo de objetividade das ciências naturais. Assim, a teoria crítica e o sujeito crítico não apenas descrevem e reconhecem a realidade social como sendo expressão de contradiçōes e de formas de dominaçōes sociais, mas também a condenam na medida em que este mundo não é o deles, "mas sim o mundo do capital". (HORKHEIMER, 1980, p. 130).

Enquanto a teoria tradicional tem o caráter pragmático e funcional - com o papel classificatório, descritivo e ordenador. A teoria crítica se orienta 
para a emancipação em relação ao todo e para a transformação deste mesmo todo, ainda que tais processos ocorram de forma mais individualizada e particularizada, contra as contradiçōes e cisōes que conhece o homem em sua realidade concreta.

Luta pelo reconhecimento de vítimas que operam transformaçōes em diversas "frentes de libertação", que esta Ética da Libertação fundamenta e legitima, poder dar uma certa orientação, a partir de critérios e princípios éticos, no dia-a-dia, para o exercício da práxis da libertação, desde as vítimas, de normas, açōes, microestruturas, instituiçōes ou sistemas de eticidade, sem ter de esperar o tempo das revoluçōes quando estas são "impossíveis". (DUSSEL, 2002, p. 13).

Dussel (2002) define o universo de sujeitos críticos concretos (vítimas), que operam mudanças e emancipaçōes em contextos históricos e sociais específicos e que lutam por reconhecimento de sua condição de sujeito, de suas lutas e de seus direitos diante da impossibilidade histórica quanto a novas "revoluçōes". O comportamento crítico segundo Dussel é orientado pela emancipação em relação à hegemonia do sistema de pensamento ocidental moderno e pela emancipação das vítimas reais e concretas quanto ao sistema-mundo ocidental moderno (excludente) e quanto ao sistema histórico e social (excluído), que define o mundo em que elas vivem suas contradiçōes e lutam por reconhecimento e emancipação.

Para mim, foi sempre a realidade da vítima a partir de sua negatividade, resistente e na exterioridade da Totalidade, que em sua libido reprimida, sua não-comida, não-vestido, não-ciência, não-felicidade, obriga, exige ética e positivamente incluir estas negatividades "faltantes" no projeto alternativo. O projeto não é meramente fruto de "minha/nossa fantasia", mas está já escrito negativamente nas necessidades atuais da vítima. Por isso, "seus verdadeiros interesses" são finalmente seus interesses invertidos nas necessidades não cumpridas, e só num articulado compromisso prático pode o crítico (filósofo, cientista, experto) chegar a descobri-los teoricamente. (DUSSEL, 2002, p. 397, nota 246).
Esta pesquisa é realizada com a orientação epistemológica desta teoria critica através do materialismo histórico e dialético criado por Karl Marx (1818-1883) e Friedrich Engels (1820-1895) e ao longo do tempo desenvolvida por estudiosos daquilo que se convencionou chamar de marxismo. Um leitor ao ter um primeiro contado com autores marxistas do século XXI pode se perguntar: por que Marx e Engels hoje? Afinal, tais autores estudaram e pesquisaram a Europa do século XVIII, em que eles poderiam contribuir numa pesquisa realizada no Brasil 150 anos depois da publicação d'O Capita? Aqui cabe o esclarecimento, realizar uma pesquisa sob a ótica marxista não é tomar cegamente as categorias que Marx e Engels encontraram em suas pesquisas e com elas tentar explicar a realidade hoje. Tampouco ter em Marx um ícone, logo ele, um grande iconoclasta. A ortodoxia marxista diz respeito ao método, isto é, ao materialismo histórico e dialético. O marxismo não é um dogma, mas um pensamento que se atualiza diante dos desafios à teoria revolucionária. É uma teoria viva, e como tal, só consegue se desenvolver se consegue conhecer e interpretar os novos fenômenos da atualidade.

O método de Marx permanece atual para análise e compreensão das relaçōes sociais capitalistas. Diferente de Durkheim que escreveu a obra As regras do método sociológico em que explica detalhadamente como é sua metodologia, Marx nunca escreveu algo semelhante, apesar de ter feito breves explanaçōes nos Grundrisse e A Ideologia Alemã, por isso José Paulo Netto (2016) afirma que é impossível apresentar o método de Marx desvinculado da pesquisa que ele de fato produziu. $\mathrm{O}$ instrumental teórico metodológico do materialismo histórico e dialético deve ser compreendido em sua integralidade, de maneira que não seja utilizado de modo incoerente com as suas características e finalidades. Afinal, trata-se de método construído a partir das circunstâncias concretas do modo de produção da sociedade capitalista, e que tem por objetivo compreender para transformar. 
Esse aparato teórico-metodológico permite compreender que as pessoas são o que são por estarem situadas num contexto histórico. Não há que se falar num sujeito abstrato, dotado de características universais. Cada mulher e cada homem estão situado no espaço e no tempo, no sentido em que vive numa época precisa, num lugar preciso, num contexto social e cultural preciso. O ser humano é um ser de raízes espaço-temporais. Em função do caráter histórico, a definição de sujeito humano não é homogênea, varia de acordo com os contextos nos qual é produzida. Muitos povos não tiveram/têm consciência da individualidade de seus membros, sendo o espaço coletivo o âmbito da identidade. Um exemplo ainda vivo dessa subjetividade coletiva são os povos indígenas, cuja identidade é percebida como a identidade da tribo, em que pese a imposição dos padrōes culturais dominantes tenha enfraquecido esta percepção.

No atual momento histórico em que as relaçōes sociais são capitalistas, há um movimento oriundo da modernidade no qual as culturas europeia e estadunidense são tidas como as únicas óticas de enxergar o mundo. Dussel (2007) esclarece que essa ótica dominante é a ótica burguesa, que, quanto a suas problemáticas específicas, não investigam todos os demais espaços políticos historicamente existentes. Ao excluir este outro plural na sua materialidade e historicidade - de suas investigaçōes e de sua filosofia, situando o mesmo na exterioridade da totalidade do sistema dominante, que logrou impor-se historicamente de forma legítima, o centro reproduz na história do pensamento político o mesmo antagonismo que ele reconheceu caracterizar o processo social de produção burguesa e que ele afirmou ser possível superar pelas condiçōes materiais próprias do sistema de produção burguesa. Antes de tudo, o centro reproduz historicamente o cancelamento da história desse outro (América Latina, por exemplo), que operou como condição de inauguração da própria história do centro e opera ainda como condição de legitimação do mesmo, no âmbito do pensamento político. Ainda segundi Dussel, a exclusão histórica desse sujeito histórico e crítico, que é o outro enquanto vítima também desta exclusão, encontra sua forma de legitimação na "enfermidade eurocêntrica" que é fundamentada na ideia segundo a qual a particularidade do centro é universal e fundamenta o evolucionismo histórico, quanto ao fato de que todas as sociedades deverão passar por ela.

A filosofia política do centro (da Europa e dos Estados Unidos) é sumamente vinculada a sua problemática. Estuda apenas seus próprios assuntos, de maneira tradicional e em funçāo de sua própria prática política. Todos os restantes espaços políticos são simplesmente desdenhados, não investigados. Crê [...] que tratando de seus problemas já terá construído uma filosofia política adequada para todo o mundo. Sua antiga enfermidade eurocêntrica a leva a pensar que sua particularidade é universal, por onde deverão passar, de uma maneira ou de outra, todos os povos da terra. (DUSSEL, 2007, p. 552).

Com a categoria da totalidade o discurso teórico do direito é uma parte integrante do todo da formação social capitalista, cuja orientação ideológica dominante serve para justificar e legitimar essa mesma ordem social. No campo jurídico as ideias modernas da racionalidade e do individualismo se conjugam abstratamente na noção de sujeito de direito, enquadrando a pessoa como um ser racionalmente capaz de manifestar sua vontade, de forma individual e autônoma. Completando a noção, temos o princípio da igualdade formal, segundo o qual todos são iguais perante ordem jurídica, desconsiderando que a formação da vontade, as condiçōes de manifestá-la e, sobretudo, de que ela seja levada em consideração, dependem de vários fatores - em especial a condição econômica.

Os direitos são produtos culturais, no âmbito dos direitos humanos, estes têm um marco bem definido: a modernidade ocidental capitalista. Ao analisar o surgimento destes direitos, como a Declaração dos Direitos do Homem e do Cidadão, 
Declaração de Direitos do Bom Povo de Virgínia, percebe-se que tais direitos nascem em um contexto onde era necessário garantir um espaço de autonomia do indivíduo frente as relaçōes do Estado Absolutista, necessário ao desenvolvimento das relações capitalistas que estavam surgindo na sociedade naquele momento.

[...] desde nuestra perspectiva teórica los derechos humanos no son algo dado y construido de una vez por todas en 1789 o en 1948, sino que se trata de procesos. Es dicir, de dinámicas e luchas históricas resultado de resistencias contra la violencia que las diferentes manifestaciones del poder del capital han ejercido contra los individuos y los colectivos. Ahora bien, no hablamos de procesos abstractos dirigidos por alguna filosofía o dialéctica histórica con pretensiones de objetividad y absolutismo; ni, asimismo, lo hacemos de un poder mistificado en alguna instancia transcendente, a partir de la cual la realidad social va emanando milagrosamente. Los procesos de lucha, a los que convencionalmente denominamos en la actualidad derechos humanos, son los que comenzaron a surgir históricamente a principios de los años setenta con las teorías neo-contractuales de la justicia y que confluyó en el llamado 'Consenso de Washington'. (FLORES, 2005, p. 219).

O direito, enquanto instrumento de controle social, enquadra as pessoas em certos padrōes de comportamento. Escolhem-se algumas dentre várias de opçōes, para transformar em padrōes abstratos e gerais, que deverão supostamente ser seguidos por todas as pessoas, ainda que as condiçōes concretas de produção e reprodução da vida simplesmente impossibilite tal adequação. Necessariamente, esta opção implica na exclusão de todas as outras opçōes. Este é um detalhe essencial do direito: ao normatizar as condutas, escolhe algumas, tidas como adequadas e exclui outras, tidas por inadequadas. Ocorre que os parâmetros utilizados para separar o adequado do inadequado, o correto do errado, o justo do injusto, é indissociável da visão ideológica dos grupos que, em última análise, dominam os rumos do direito. Estes grupos se identificam com uma elite proprietária, masculina, branca, cristā, heterossexual, que acaba por desconsiderar as demais realidades humanas concretas que se afastam da sua.

A categoria de sujeito de direito se apresenta dessa forma abstrata, ocultando suas raízes histórico-econômicas que estão totalmente implicadas com a ascensão do modo de produção capitalista - o sujeito de direito é o proprietário. A sua condição de sujeito é estabelecida no ato de troca que ocorre no comércio e é em função desse ato que foi tão caro à burguesia assegurar o direito à liberdade - liberdade para o comércio e para explorar os trabalhadores num contrato de trabalho cujas condições são "livremente" estabelecidas. O direito não é neutro, já que a regulamentação de determinada relação social corresponde também a uma relação de dominação, onde os conflitos são neutralizados a partir da perspectiva dominante (FLORES, 2005). Dentro deste conjunto de práticas que apresentam um potencial emancipador, é possível destacar aquelas lutas por demandas específicas: moradia, mobilidade, saneamento básico, segurança, educação, que se encontram inscritas em um contexto muito mais abrangente de luta pela própria cidade, que no fundo corresponde a uma luta anticapitalista. Neste trabalho a cidade é entendida como

El producto físico, político y cultural complejo, europeo y mediterraneo y también americano y asiático, que hemos caracterizado em nuestra cultura, em nuestro imaginario y em nuestros valores como concentración de plobación y atividades, mezcla social y funcional, capacidad de autogobierno y ámbito de identificación simbólica y de participación cívica (BORJA; MUXÍ, 2003, pp. 103-104).

Este "produto" está intimamente conectado com o sistema capitalista, uma vez que surge da concentração (geográfica e social) dos excedentes de produção, onde os recursos necessários a suprir as necessidades urbanas, também são produzidos pelo capitalismo que depende, por sua vez, 
da urbanização para absorver uma gama de excedentes gerados em busca da mais-valia.

\section{0 movimento dialético do espaço urbano}

Os conteúdos que explicam a forma de ser da cidade são conteúdos sociais, no sentido de que a cidade é um produto social, mas também é condição para a reprodução da sociedade, o que inclui os interesses de reprodução do capital, mas também os desejos e necessidades de reprodução da vida. Por isso, a cidade está sempre em disputa. As possibilidades de apropriação, do uso, da festa, implicam no conflito com os interesses hegemônicos. Produzida como mercadoria, vendida em fragmentos, estendida, dominada, a cidade de repente se apresenta ao habitante como externalidade, uma vez que embora seu processo de produção seja social, sua apropriação é privada. (ALVAREZ, 2015, p. 4)

As cidades surgem no momento da sedentarizarão do homem, com o surgimento da agricultura. O homem deixa de ser coletor e caçador e passar a usar o seu trabalho para modificar a natureza. No instante em que a natureza é apropriada pelo homem e transformada através do trabalho, ela passar a ser criação humana. Este trabalho não tem por finalidade se aprofundar no histórico de formação das cidades, mas sim nos conceitos de cidade e urbano. Logo, não serão abordas questōes de produção do espaço urbano antes do capitalismo.

Com esse recorte temporal estabelecido, pode-se afirmar que a industrialização e a urbanização são fenômenos vinculados, uma vez que foi nas cidades que as indústrias foram criadas e se estabeleceram, em locais onde haviam mão de obra necessária, serviços de transporte para evacuação da produção, mercado consumidor e infraestrutura necessária para sua ampliação. Assim, só é possível tratar sobre as relações do capitalismo na produção do espaço após a Revolução Industrial.
O crescimento das cidades em detrimento das áreas agrícolas, em função do aumento de oportunidades de empregos oriundos das industrias e do sistema capitalista, contribuíram para a produção do espaço urbano e, consequentemente, o sentido do espaço como produto para a produção social. Assim, as cidades evoluíram vinculadas ao crescimento da população, que vai formando sua estrutura sociopolítica, econômica e religiosa.

A cidade enquanto construção humana é um produto histórico social e nesta dimensão aparece como trabalho materializado, acumulado ao longo do processo histórico de uma série de gerações. Expressão e significação da vida humana, obra e produto, processo histórico cumulativo, a cidade contem e revela açōes passadas, ao mesmo tempo em que o futuro, que se constrói nas tramas do presente - o que nos coloca diante da impossibilidade de pensar a cidade separada da sociedade e do momento histórico analisado (CARLOS, 2007a, p.11)

Logo, estudar a construção do espaço é um processo contraditório e que precisa ser analisado como um todo, como um conjunto de fatores que tornam a reprodução do espaço pelo capital ligado diretamente a vida social, política e econômica e determinada pelo momento histórico.

O conceito de formação espacial está associado à formação econômica e social, cuja origem encontra-se no materialismo histórico e na dialética marxista. O desenvolvimento da teoria crítica da geografia a partir dos anos 70 tem por premissa o estudo do espaço enquanto fator decisivo para a estruturação de uma totalidade, de uma lógica de um sistema. Atribui ao espaço uma condição física para a viabilização da produção, sendo que as diferenças entre os lugares são consequências de diferentes formaçōes sociais e econômicas, que representam modos de produção específicos.

Os responsáveis pela construção do espaço são os diversos atores sociais, como os proprietários dos meios de produção, os grandes proprietários de terras, o Estado e grupos sociais específicos. 
Assim, o conflito é inerente a produção do espaço urbano, uma vez que há diversos interesses políticos e econômicos em disputa. Harvey (2005, p. 170) explica a questão dizendo que a cidade deve ser compreendida como uma arena onde diversos agentes sociais se confrontam e onde os diversos interesses desses agentes "interagem por meio de uma configuração especifica de práticas espaciais entrelaçadas".

Nos dias atuais, desde a década de 1970, vigora um regime de acumulação de capital que Harvey (2005) chama de "ofensiva neoliberal", que é o resultado dos ciclos de produção/estagnação/crise inerentes ao sistema capitalista. O neoliberalismo é uma forma política-ideológica que valoriza o empreendedorismo, a meritocracia, isto é, o pensamento de que o que as pessoas conseguem dependem somente delas, do esforço pessoal. As pessoas devem competir umas com as outras no mercado e crescer. O sistema neoliberal se torna hegemônico no mundo capitalista.

\section{Capitalismo e a cidade como empresa/mercadoria}

Com a crise financeira dos anos de 1970, o sistema capitalista entra numa crise de sobreacumulação. As empresas veem a necessidade de diversificar sua forma de produção e começam a abrir suas açōes no mercado financeiro. Esse novo processo do capitalismo estava baseado mais no capital fictício do que na produção do valor propriamente dito, isto é, do corpo na produção de objetos. Segundo Harvey (2014a), esse processo de sobreacumulação seria resultado da própria exploração do sistema capitalista, uma vez que os trabalhadores produzem mais do que do que os seus salários podem comprar. Assim, os capitalistas são obrigados a reinvestir esse excedente do capital de forma a trazer maiores lucros.

Os capitalistas então resolveram investir esse capital excedente nas cidades, prioritariamente na revitalização de áreas centrais e portuárias de- gradas, pois viram na (re)construção do espaço uma possibilidade de aumentar a produção da mais-valia. Uma vez que além poder se diminuir a sobreacumulação, as intervençōes urbanas demandam muitas mãos de obra, o que diminui o desemprego e, consequente, aumenta o número de consumidores dos produtos das empresas. Ao mesmo tempo, ao se construir novos espaços e novas infraestruturas, o espaço é valorizado financeiramente, em um processo de especulação imobiliária. Harvey argumenta que a urbanização configura uma forma essencial no que tange à absorção dos excedentes produzidos pelo capitalismo (tanto de capital, quanto de trabalho), onde:

[...] a produção de espaço e dos monopólios espa-
ciais tornam-se parte integrante da dinâmica da
acumulação, não apenas em virtude da natureza
dos padrōes mutáveis do fluxo de mercadorias no
espaço, mas em virtude da natureza mesma dos
espaços e lugares criados e produzidos em que
esses movimentos ocorrem. (HARVEY, 2014, p. 92).

Podemos concluir que a urbanização desempenhou um papel crucial na absorção de excedentes de capital, e que o tem feito em escala geográfica cada vez maior, mas ao preço de processos florescentes de destruição criativa que implicam a desapropriação das massas urbanas de todo $e$ qualquer direito à cidade (HARVEY, 2014, p. 59).

Com isso, deu-se início ao modelo de planejamento estratégico, fundamentados nos planejamentos econômicos das grandes corporaçōes e voltados exclusivamente para atração de investimentos externos para a cidade. Nesse sentido, as cidades elaboram planos estratégicos para competir em um "mercado global" pelo investimento, desenvolvendo os elementos de seu território que representem a imagem de uma cidade segura, pronta para receber o capital internacional (Sanchéz, 1999). É vendida a ideia de que a competitividade entre as cidades demanda investimentos, muitas vezes públicos, na construção de uma cidade voltada para a venda de sua imagem, da sua modernidade e da sua segurança. Os planos estratégicos 
são implementados nas cidades num contexto de competitividade e desafios como os das empresas. No entanto, os recursos públicos fazem investimentos para gerar grandes centros urbanos, ao invés de investir em áreas sociais com demandas mais necessárias e urgentes.

Vainer (2002a) chama a atenção que todas as cidades acabam por vender o mesmo ideário e o mesmos "produtos", uma vez que os compradores têm sempre as mesmas necessidades. As cidades apresentam as mesmas estruturas urbanas construídas nos seus centros econômicos e turísticos, pois como cidades globais, o desenvolvimento das áreas centrais das cidades globais se encontra nas mãos das mesmas instituições financeiras que são submissas as mesmas multinacionais. Então, no fundo, não são as cidades que competem entre si, mas sim as empresas que buscam localizaçōes favoráveis as suas atividades econômicas. Logo, as cidades globais são aquelas que concentram os principais mercados financeiros e empresas prestadoras de serviços.

Historicamente esse modelo de cidade foi "vendido" à população pelos meios de comunicação e incorporado ao cotidiano, após grandes períodos de recessão econômica sendo, portanto, um ideário de mudança positiva, de dinamismo, de geração de renda e atratividade para as cidades. Castells e Borja (1996) apontam que o processo de crise foi um dos principais fatores que levaram os governantes das grandes metrópoles mundiais a buscarem uma nova forma de atrair investimentos. No entanto, esses autores enxergam as cidades como sujeitos ao afirmarem que o um dos fatores para implantação dos planejamentos estratégicos em uma localidade se faz através de uma vontade conjunta, sem levarem em consideração que os interesses sociais são na verdade conflitantes. Não seria possível afirmar então, de uma forma que não seja ideológica, que existe um consenso público.

Logo, mister destacar que a representação do imaginário da cidade nada mais é do que uma construção ideológica, que consequentemente permite a condição de cidadania para uma parcela pequena na da população produzir a cidade como um negócio, como uma fonte de acumulação. Portanto, a parte da cidade ocupada pelas elites econômicas praticamente representa a cidade si, num imaginário coletivo que esconde a cidade como ela realmente é. Essa representação está ligada a interesses econômicos e imobiliários, produzindo os vazios urbanos ou a "renovação" de espaços destinados à valorização $e$ especulação. O resultado é a segregação urbana.

Nesse processo não só constrói o novo, mas destrói o velho. A destruição é necessária no processo de revalorização. O setor imobiliário cria espaços novos e faz as pessoas acreditarem que morar neles é melhor do que nos espaços anteriores que esse mesmo setor criou no passado. Tanto ideologicamente, através da propaganda e da criação de novas necessidades sociais como também na forma como esses espaços são construídos, nos materiais utilizados - em sua maioria produzidos para não durarem muito tempo e, portanto, continuarem o ciclo de renovação. Esse processo ideológico produz a ideia do que é ser feliz, do que é morar, do que é o urbano, do que é vivenciar a cidade, ao mesmo tempo que nega o velho, fisicamente e socialmente.

Para implementar esse modelo de cidade, é interessante para os capitalistas ter o apoio popular, pois quanto menos resistência a população oferecer melhor. A realização de um megaevento é um meio de se conseguir esse apoio popular, pois pode fazer a população se unir através do desejo de realizá-lo. Rose Compans explica o que são os megaeventos e por que eles têm potencial de fazer a população se unir:

São programas de vários equipamentos que beneficiam economicamente uma cidade inteira, como jogos olímpicos, as exposições internacionais, etc. Promovem a imagem da cidade, ao mesmo tempo que adotam, através de financiamentos externos, a cidade de equipamentos urbanos numa escala impensável para ser custea- 
da exclusivamente com o orçamento municipal, adquirindo por esta razão um forte poder simbólico, como ocorreu em Barcelona e em Sevilla (COMPANS, 1996).

Capaz de mobilizar elementos simbólicos, cujo legitimidade aparece ao senso comum como algo dado, como a ideia dos "legados" e dos ideais universalistas da "celebração esportiva", os megaeventos esportivos conseguem promover uma radicalização do discurso consensualista em tal nível o que a uma simples ideia de uma ação ou omissão passível de determinar um eventual obstáculo ao projeto olímpico é posta como inaceitável. Desse modo, em forma de decretos e medidas provisórias, ou de projetos de leis votados de maneira atropelada, um novo quadro institucional foi criado no emaranhado de novas leis que se articulam de forma transescalar para atender determinados [...] interesses que se colocam como hegemônicos sem admitir qualquer nível de questionamento. A expressão "é necessário para honrar nossos compromissos de candidatura", parece mágica. Dentro do discurso dominante ela ganha, literalmente, "força de lei'. (Gusmão, 2012, p.10-11).

\section{Rio de Janeiro e o urbanismo olímpico}

Megaeventos são instrumentos de poder, distantes das realidades e dos problemas urbanos $e$ seus efeitos. Os Jogos Olímpicos são uma estrutura que representa a integração do mercado com - Estado, uma estrutura pautada e regida pelo capitalismo. A enorme disputa das cidades para sediarem esse megaevento, dentro do contexto dos planos estratégicos, ocasiona mudanças rápidas e bruscas no espaço urbano, que tem que ser adaptado para as modalidades esportivas que serão disputadas. Muitos planos estagnados por falta verba passam a poder serem concretizado graças as verbas que chegam para o megaevento.

Neste contexto, no ano de 1993 começa o planejamento da cidade do Rio de Janeiro como sede dos Jogos Olímpicos. Essa iniciativa foi do então prefeito César Maia, que realizou um acordo com a Associação Comercial (ACRJ) e a Federação de
Indústrias (FIRJAN), dando início a elaboração do Plano Estratégico do Rio de Janeiro (PECRJ). Importante dizer que a cidade carioca tomou como exemplo para nortear esse processo o modelo de cidade-empresa adotado por Barcelona para sediar as Olímpiadas de 1992, no qual um dos pilares é parceria público-privada (PPP). Tal parceria flexibiliza o modus operandi positivado no plano diretor, no que concerne a participação na elaboração dos projetos de cidade, construindo-se uma política que responde mais aos vetores financeiros do que aos da democratização urbana. A título de exemplo, a empresa vencedora de licitação promovida pela prefeitura, poderá explorar comercialmente $75 \%$ da área total do Parque Olímpico após as Olimpíadas.

\begin{abstract}
Se durante um largo período o debate acerca da questão urbana remetia, entre outros, a temas como o crescimento desordenado, reprodução da força de trabalho, equipamentos de consumo coletivo, movimentos sociais urbanos, racionalização do uso do solo, a nova questão urbana teria, agora, como nexo central a problemática da competitividade urbana. (VAINER, 1999, p.75)
\end{abstract}

Assim, em 1994, 46 empresas e associações empresarias realizaram o consórcio mantedor do PECRJ, seguido da contratação da empresa catalã Tecnologies Urbanas Barcelona S.A. (TSUBASA) para assumir a Direção Executiva do Plano. Ainda em 1994, formou-se a cúpula do PECRJ, chamado de Conselho da Cidade, ela tinha uma composição heterogênea:

[...] mais de 300 membros. Dentre esses é possível contar cerca de 20 entidades associativas populares e sindicatos, bem como algumas instituiçōes acadêmicas. Muitas empresas, o Lyons Club, a Liga Independente das Escolas de Samba, o Tijuca Tênis Clube, organizaçōes não governamentais para todos os gostos.... À primeira vista, temos aí uma razoável, embora não proporcional, representação do espectro social e cultural da cidade. Os critérios, no entanto, não são nada claros: há indivíduos (personalidades), empresas, entidades representativas, lado a lado. (VAINER, 1996). 
O Conselho da Cidade possuía um Conselho Diretor, este menor e mais hegemônico, formado em sua maioria por empresários e políticos conservadores e sem representantes sindicais e comunitárias. Na prática o que se viu foi o Conselho da Cidade sem poder deliberativo, tendo como função apenas homologar as decisōes tomadas pelo Conselho Diretor. Este processo culminou na escolha da cidade carioca para sediar os Jogos Olímpicos de 2016. A escolha foi feita em 2009, por conta disso, logo em seguida, em 08 de outubro deste mesmo ano, a prefeitura anunciou a necessidade de remoção de mais de 3.500 famílias de 6 comunidades das Zonas Oeste e Norte, dentre as quais encontra-se a Vila Autódromo, que se tornou o principal símbolo de resistência contra as remoçōes.

\section{Vila Autódromo: luta e resistência}

Originalmente uma vila de pescadores, Vila Autódromo torna-se, nos anos 1970, uma oportunidade para a moradia de centenas de migrantes operários e trabalhadores informais que chegaram à região para a construção do autódromo de Jacarepaguá, do metrô e dos novos empreendimentos imobiliários que despontavam no local. A Vila é um exemplo de experiência autônoma, à margem do poder público e de suas regras. $\mathrm{O}$ bairro que historicamente sofre com omissões de prestaçōes positivas por parte do Estado, foi construído pelas mãos dos próprios moradores.

Em 1993, no primeiro mandato do prefeito César Maia, a comunidade sofreu sua primeira tentativa de remoção, através de uma ação civil pública (Processo № 0081973-19.1993.8.19.0001) sob a justificativa de que a Vila causava danos estéticos ambientais. De acordo com Compans (2007) essa é uma tática utilizada pelo poder público para realizar desapropriaçōes em áreas que interessam o capital imobiliário. Ainda segundo a autora, os objetivos reais do poder público são disfarçados através de um discurso de que essas áreas de interesse representam um risco ambien- tal, uma vez que há uma alta densidade populacional e pela ocupação de terrenos íngremes, na beira de córregos que poderiam provocar desastres ambientais. Contudo:

\begin{abstract}
As áreas ambientais frágeis - beira de córregos, rios e reservatórios, encostas íngremes, mangues, áreas alagáveis, fundos de vale - que, por essa condição, merecem legislação especifica e não interessam ao mercado legal, são as que "sobram" para a moradia de grande parte da população [...] eles são vistos como inimigos da qualidade de vida e do meio ambiente. (MARICATO, 2002, p. 163).
\end{abstract}

Até 1997, 247 famílias tinham conseguido títulos de propriedade para uso com fim de moradia (Plano popular, 2012. P. 8-9). As famílias beneficiadas com a titulação começaram a fazer meIhorias em seus imóveis, pois se sentiam seguras por terem a concessōes de uso. Contudo, por conta da preparação dos Jogos Pan Americanos de 2007, os moradores precisaram resistir novamente a açōes propostas pela Prefeitura, que alegava a necessidade de remoçōes, uma vez que que os moradores habitam uma "área risco".

As açōes da Prefeitura ganham mais força quando em 2009 a cidade do Rio de Janeiro foi eleita como sede dos Jogos Olímpicos de 2016. É um movimento de criação de uma nova centralidade da cidade na região da Barra da Tijuca, com intenso investimento em infraestrutura por parte do Estado, cujo as principais avenidas são Abelardo Bueno e Salvador Allende, cujo cruzamento é onde se localiza a Vila Autódromo. A Vila que em outros tempos era formada por 700 famílias, hoje só têm 20 e as remanescentes enfrentaram grandes empecilhos por uma vida digna.

Além disso, os moradores estimam que mais de 500 árvores foram demolidas no local. Tendo em vista tamanha importância da manutenção da flora, e o impacto direto que sua retirada causa aos moradores, a prefeitura não garantiu o direito à cidade ao deliberar sozinha sobre o assunto. Provavelmente, se os moradores fossem consul- 
tados, essa devastação ambiental não ocorreria. Já que havia uma forte ligação da população com as árvores, era consenso que elas melhoram a qualidade de vida. Por exemplo, Delmo Oliveira, que viveu 26 anos na Vila, junto com seu filho, planou 7600 mudas na comunidade, e 3 anos após o início do plantio, 2 ruas já estavam repletas de árvores. Elas foram plantadas para que os moradores tivessem o conforto de andar até o ponto de ônibus na sombra. Esse desmatamento não coaduna com o Plano de Gestão da Sustentabilidade dos Jogos Rio 2016, que prevê iniciativas para amenizar a emissão de gás carbônico relacionada aos Jogos.

Com a cidade carioca eleita sede olímpica, o primeiro argumento usado pelo governo municipal em prol da remoção da Vila, foi a necessidade de ampliação das Avenidas Abelardo Bueno e Salvador Allende. Depois a justificativa passou a ser a necessidade construir o Parque Olímpico no local. Em seguida, a prefeitura mudou o discurso novamente, e apontou a necessidade de se fazer a ligação viária entre as novas vias Transcarioca e Transolímpica para implantar o modelo BRT. Assim, nota-se como justificativa para tal projeto era frágil, uma vez que foi sendo modificada ao longo dos anos.

O acesso a serviços públicos no local é limitado, uma vez que os governos estadual e municipal têm restringido seus investimentos na área, inclusive como forma de pressionar a população para induzi-la a aceitar a remoção. Não há creche próxima e o programa saúde da família de posto de saúde próximo não atende a comunidade.

O projeto da prefeitura para Vila Autódromo recebeu o nome de Parque Carioca e foi pensado sem qualquer discussão com a população. O projeto prevê a construção de blocos de apartamento idênticos em condomínio, replicando sistemas de valores da classe média. O terreno utilizado para construção dos apartamentos se localiza a um quilometro de distância da atual Vila Autódromo, na 13 Estrada dos Bandeirantes,
Camorim. Trate-se de uma antiga área de mineração, negligenciada pelo poder público, e onde há uma área reservada para habitação dos egressos da Vila Autódromo e de outras comunidades removidas. Nesse cenário, fruto da ausência de diálogo, há o rompimento de laços sociais e territoriais construídos ao longo das últimas quatro décadas pela comunidade.

A fim de resistir aos planos da prefeitura, a Associação de Moradores de forma autônoma e com o apoio dos movimentos sociais e com o auxílio técnico da Universidade Federal Fluminense e da Universidade Federal do Rio de Janeiro, elaboram um projeto alternativo: o Plano Popular da Vila Autódromo (PPVA). A ajuda universitária foi importante, uma vez que a prefeitura se resguardava utilizando uma argumentação "técnica". Com a ajuda das faculdades, os moradores demonstraram a possibilidade de permanência no local e viabilidade de um projeto de urbanização. O trabalho entre os assessores e os moradores foi através de um processo dialógico realizado em conselhos.

O Plano Popular de Vila Autódromo, ao contrário do projeto do Parque Carioca, é o resultado e a expressão da resistência e da defesa dos moradores da Vila Autódromo da permanência na área. Contém açōes voltadas para o desenvolvimento social, cultural, econômico e urbano, abrangendo melhorias urbanísticas dos espaços públicos e privados e do saneamento ambiental. Reafirma o direito da população à área atualmente ocupada, reunindo propostas técnicas que comprovam essa possibilidade e também a da melhoria das condiçōes habitacionais e ambientais existentes. Nele, todas as açōes surgiram a partir das demandas manifestadas pelos moradores e de sua visão sobre seu local de moradia. (VAINER et al., 2013, p. 17)

Os dois projetos são antagônicos, enquanto a prefeitura propõe remoçōes, demolindo todas as casas existentes, afirmando a impossibilidade de urbanização do bairro, por causa da necessidade de preservação ambiental, o Plano Popular sus- 
tenta que os moradores permaneçam no local e demonstra a possibilidade de urbanização

O Plano Popular da Vila Autódromo é fruto da resistência travada pelos moradores. O Plano demonstra tecnicamente a viabilidade de permanência dos moradores no local, além de meIhorias das condiçōes habitacionais e ambientais existentes. Todas as propostas elaboradas foram pensadas a partir das demandas e opiniōes apresentadas pelos moradores.

Dentre outros pontos e objetivos do PPVA, destaca-se (i) a afirmação do direito e a possibilidade da permanência da comunidade na área atual e rejeita a remoção involuntária de qualquer morador; (ii) todos os atuais moradores da Vila Autódromo terão acesso a moradia adequada dentro da comunidade, independentemente de sua condição de ocupação atual, área ocupada e renda; (iii) todos os atuais moradores da Vila Autódromo terão garantia de condições adequadas para a realização de atividades econômicas dentro da comunidade, e condiçōes de transporte e acessibilidade para o trabalho; (iv) todos os atuais moradores da Vila Autódromo terão garantia de acesso a espaços públicos e condiçōes para o desenvolvimento de atividades de cultura, esporte e lazer na comunidade, e condiçōes de acesso aos equipamentos públicos da cidade; (v) o PPVA é parte da luta de todas as comunidades da cidade do Rio de Janeiro, do Estado e do país contra a violação do direito à moradia e pelo respeito dos direitos humanos pelos projetos voltados para a Copa 2014 e os Jogos Olímpicos 2016

Os processos de remoção involuntária raramente consideram a articulação concreta entre o exercício dos direitos e o espaço urbano. Das relaçōes com o território surgem diferentes formas de trabalho, serviços prestados pelos autônomos e informais, redes de solidariedade social, contatos com os vizinhos, amizades para as crianças, convívios na escola, contatos com os profissionais de saúde, etc. O que para o poder público é um simples "reassentamento", para as famílias é a uma mudança total nas formas de vida e de acesso, mesmo quando precário, ao direito à moradia. Este direito não compreende somente o direito de ter um abrigo, neste direito está incluso a segurança legal da posse, a disponibilidade de serviços, materiais e infraestrutura, o custo acessível, a habitabilidade, a acessibilidade, localização e adequação cultural, em uma vertente associada ao ideário de direito à cidade.

A efetivação deste direito integra o conteúdo de cidade social, fazendo com que a questão habitacional esteja inserida no complexo feixe de problemas urbanos, seja pela ausência de habitação, seja pela precariedade daquelas existentes, presentes em muitas cidades, exigindo a formulação e a implementação de políticas públicas adequadas. Neste contexto, destacam-se os movimentos sociais de luta pela moradia ganhando relevância na cidade do Rio de Janeiro as ocupaçōes: Quilombo das Guerreiras, Zumbi dos Palmares, Chiquinha Gonzaga, Flor do Asfalto e Machado de Assis, todas localizadas em prédios públicos situados no centro da cidade, tendo as duas últimas ocupaçōes citadas, sofrido um desalojamento violento diante da implementação do projeto Porto Maravilha, na região portuária da cidade. (BELLO; FERREIRA; DIAS, 2016, p.25)

\section{A luta pelo direito a cidade como luta de classes}

O espaço público da cidade do Rio de Janeiro está fragmentado, privatizado e segregado. Há bairros ricos com todos os serviços públicos disponíveis, espaços de lazer e segurança, ao mesmo tempo que há bairros pobres, ocupaçōes com habitaçōes precárias, sem educação e saúde, sem transporte público adequado, com moradores amedrontados por uma polícia que criminaliza a pobreza. Nesse cenário dois modelos de cidadania estão em disputa: enquanto movimentos sociais, sociedade civil organizada, militantes, reivindicam uma cidadania ativa, de participação direta de cidadãos na política da comunidade; grupos hegemônicos, notadamente empresários e políticos conserva- 
dores, tentam manter a cidadania passiva, como status e titularidade de direitos e deveres, concepção que prevalece na era moderna.

Este segundo grupo através da realização de megaeventos tem transformado a cidade carioca numa mercadoria, de forma que a gestão do espaço urbano é impulsionada pelos "interesses de acumulação do capital" (BAVA, 2014), sobrepondo-se aos interesses da coletividade. Assim:

[...] ela [a cidade] é um produto ou, em outras palavras, também um grande negócio, especialmente para os capitais que embolsam, com sua produção e exploração, lucros, juros e rendas. Há uma disputa básica, como um pano de fundo, entre aqueles que querem dela melhores condiçōes de vida e aquele que visam apenas extrair ganhos. (MARICATO,2013, p. 20).

Assim, é possível notar que o papel do Estado na reprodução do espaço tem a dominação de classes como um fator dominante. A reprodução dos espaços sempre será desigual, pois reproduz o processo de produção do sistema capitalista. O Estado defende interesses particulares de uma classe privilegiada em uma sociedade capitalista de classes. No caso da Vila Autódromo todos os fatores foram desfavoráveis a luta pela permanência, mesmo com os instrumentos normativos que davam aos moradores titulação de propriedade.

O real objetivo desse processo acelerado de remoçōes em determinadas áreas estratégicas da cidade do Rio de Janeiro é o de se promover gentrificação sob o rótulo de "modernizaçāo". Gentrificação é o processo no qual uma área degradada sofre intervenções que aumentam o valor imobiliário desse lugar, o que ocasiona a marginalização de seus moradores, uma vez que estes não têm como arcar com as despesas do novo custo de vida do local.

O projeto da prefeitura para a Vila Autódromo tem como destinação atender a especulação imobiliária, através de uma valorização de áreas tradicionalmente descuidadas pelo poder público e desprovidas de serviços sociais, para posterior comercialização no mercado financeiro e atração de grandes centros empresariais. A Vila Autódromo não foi um caso isolado, ela é um exemplo dentre outros, como a comunidade do Horto e zona portuária. Todos fazem parte de uma lógica de governo que transforma a cidade em mercadoria.

No dia 13.06.2011, em cerimônia realizada nas instalaçōes do Porto, o prefeito Eduardo Paes anunciou a concretização da maior Parceria Público-Privada já feita no Brasil. O Município do Rio de Janeiro firmou uma PPP com o Consórcio Porto Novo (integrado pelas construtoras OAS, Odebrecht e Carioca Engenharia), no valor de cerca de R\$ 8 bilhōes, que será repassado pelo consórcio à prefeitura ao longo dos próximos 15 anos, tão logo seja regularizada a venda de diversos terrenos na região da Zona Portuária, cujo perímetro é de $5.000 .000 \mathrm{~m}^{2}$.

Na ocasiāo também foi divulgado que o Fundo de Investimento Imobiliário Porto Maravilha, controlado pela CEF, utilizando-se de recursos do FGTS (leia-se, dos trabalhadores), comprou todos os 6,4 milhões de títulos disponibilizados do CEPACS (certificado de potencial adicional construtivo) pelo valor de R\$3,5 bilhōes. Posteriormente, estes títulos serão colocados à venda no mercado com uma expectativa de rendimento de $12 \%$ ao ano" (BELLO, 2013, p. 283-284).

Na sociedade capitalista as cidades são fundamentadas em formas excludentes de uso e ocupação do solo urbano na medida em que segregam os locais de moradia das classes populares. Movimentos populares lutam por cidades que atendam às necessidades reais da população aglutinando suas bandeiras de luta em torno da pauta da reforma urbana e do direito à cidade. O direito à cidade é o direito que todos têm de participar diretamente na construção do planejamento urbano. $\mathrm{O}$ que pode contribuir para que as cidades cumpram sua função social ao repartir de forma equilibrada os bens que nela são produzidos, tais como: cultura, lazer, riquezas materiais, ou seja, que as cidades sejam apropriadas de forma coletiva. 
O direito à cidade não pode ser concebido com um simples direito de visita ou de retorno às cidades tradicionais. Só pode ser formulado como direito à vida urbana, transformada, renovada. Pouco importa que o tecido urbano encerre em si o campo e aquilo que sobrevive da vida camponesa conquanto que o "urbano", lugar do encontro, prioridade do valor de uso, inscrição no espaço de um tempo promovido à posição de supremo bem entre os bens, encontre sua base morfológica, sua realização prático-sensível. (LEFEBVRE, 2015).

O modelo de cidade-empresa inspirado em Barcelona tem se mostrado nociva aos direitos humanos dos cariocas, como alertava Bendix (1996), é preciso se desprender do entendimento de que o progresso de quaisquer sociedades seja atrelado ao desenvolvimento social e ao paradigma do processo de industrialização europeus.

Para o marxismo, o direito à cidade é o direito de transformar a cidade-mercadoria, apropriada pelo capital, em cidades que atendam as reais necessidades humanas. Ao longo da história as cidades foram mais regidas pelo capital do que pelas pessoas. Então, necessariamente, lutar pelo direito à cidade é lutar contra o capital. É lutar para tirar o processo de produção e reprodução das cidades das mãos do capital imobiliário especulativo, de forma a produzirem uma cidade com base no valor de uso e que atenda realmente aos interesses das pessoas. Assim, é possível afirmar que a luta pelo direito à cidade é uma luta entre classes. Enquanto os agentes do capital imobiliário lutam para apropriar a cidade do Rio de Janeiro como mercadoria, a massa dos trabalhadores busca na cidade a fruição plena de suas potencialidades.

No caso da Vila Autódromo, ao invés de propor remoçōes custosas e indesejadas, o poder público deveria reconhecer e ampliar iniciativas criadas pelos próprios moradores, investindo em urbanização com participação e decisão popular, regularização fundiária, assistência técnica gratuita, políticas de transferência e geração de renda, estímulo às redes sociais e culturais existentes, proteção do trabalhador informal e do pequeno comerciante, acesso à mobilidade urbana, a todos os serviços públicos e aos demais direitos da cidade.

\section{Biblografia}

BAVA, Silvio Caccia. A cidade como mercadoria. In: Le Monde Diplonatique Brasil. Disponível em: ‘https://www. diplomatique.org.br/artigo.php?id=1464. Acesso em: 10 jun. 2014

BELLO, Enzo. A cidadania na luta política dos movimentos sociais urbanos. Caxias do Sul: EDUCS, 2013.

FERREIRA, E. F. B. ; RIBEIRO, M D. O urbanismo global e o desafio da gestão participativa da cidade e da formulação de políticas públicas direcionadas à efetivação da moradia adequada. In: Célia Barbosa Abreu et al. (Org.). Escritos Menores sobre Direitos Fundamentais. v. 2. 1ed.Niterói: Editora do Programa de Pós-Graduação em Sociologia e Direito da Universidade Federal Fluminense, 2016, v. 7, p. 23-28.

BENDIX, R. 1996. Construção Nacional e Cidadania: estudos de nossa ordem social em mudança. São Paulo, EDUS P, $401 \mathrm{p}$.

BORJA, Jordi; MUXÍ, Zaida. El espacio público: ciudad y ciudadanía. Barcelona: Electa, 2003.

COMPANS, Rose. A cidade contra a favela. Revista Brasileira de Estudos Urbanos e Regionais, v.9, n.1, p. 83-99, 2007.

CASTELLS, Manuel. A questão urbana. Rio de Janeiro: Paz e Terra, 2009.

. BORJA, Jordi. As cidades como atores políticos. Novos Estudos, CEBRAp, n.45, p.152-166, jul. 166.

DUSSEL, Enrique. Ética da libertação: na idade da globalização e da exclusão. Petrópolis: Vozes, 2002.

Política de la liberación: história mundial y crítica. Madrid: Trotta, 2007.

BRASIL Constituição da República Federativa do Brasil, de 05 de outubro de 1988.

BRASIL Lei 10.257, de 10 de julho de 2001.

FALBO, Ricardo Nery. Reflexōes epistemológicas sobre o direito e a prática da pesquisa jurídica. Revista Direito e Práxis, Rio de Janeiro, v. 3, n. 2, p. 194-228, 2011. Disponível em: «http://www.epublicacoes.uerj.br/index.php/revistaceaju/article/view/2700r. Acesso em: 14 de junho de 2017. 
FLORES, Joaquín Herrera. Los derechos humanos como produtos culturales: Crítica del humanismo abstracto. Madrid: Los libros de la catarata, 2005.

GALLARDO, Helio. Teoria crítica: matriz e possibilidades de direitos humanos. São Paulo: Unesp, 2014.

HARVEY, David. Cidades rebeldes: do direito à cidade à revolução urbana. São Paulo: Martins Fontes, 2014.

HOKHEIMER, M. Teoria tradicional e teoria crítica. São Paulo: Abril Cultural, 1980. (Coleção Os Pensadores).

LEFEBVRE, Henri. $\mathbf{0}$ direito à cidade. $5^{\mathrm{a}}$ ed. São Paulo: Centauro, 2015.

MACHADO, F. A. S. Direito à cidade, um direito humano? Reflexōes à luz da teoria crítica. In: BERNER, V. O. B.; JUCÁ, R. L C.; MORAES, H. M. (Org). Teoria critica, descolonialidade e direitos humanos. Freitas Bastos Editora, 2016.

MARICATO, Ermínia. Habitação e cidade. São Paulo: Atual, 1997.

As ideias fora do lugar e o lugar fora das ideias: Planejamento urbano no Brasil. In: ARANTES, Otília; VAINER, Carlos \& MARICATO, Ermínia (Org.). A cidade do Pensamento único: Desmanchando consensos. Petrópolis: Editora Vozes, 2002.

et al. Cidades rebeldes: Passe Livre e as manifestaçōes que tomaram as ruas do Brasil. 1 ed. São Paulo: Boitempo: Carta Maior, 2013. p. 19-26.

MARX, Karl; ENGELS, Friedrich [1845-1846]. A ideologia alemã (I Feuerbach). Trad. de José Carlos Bruni e Marcos Aurélio Nogueira. 5. ed. São Paulo: Hucitec, 1986.
PLANO POPULAR, Vila Autódromo, 2012. Plano de Desenvolvimento Urbano, Econômico, Social e Cultural. Disponível em: http://comitepopulario.files.wordpress.com/ planopopularvilaautodromo.pdf. Acesso em nov. 2016.

RODRIGUES, M. R. A realidade social das ocupaçōes em áreas de risco: um descompasso com o direito humano à moradia adequada. In: Célia Barbosa Abreu et al (Org.). Escritos Menores sobre Direitos Fundamentais. 1ed. Niterói: Editora do Programa de Pós-Graduação em Sociologia e Direito da Universidade Federal Fluminense, 2016, v. 12 , p. 54-59.

SÁNCHEZ, Fernanda. Políticas Urbanas em Renovação: Uma leitura crítica dos modelos emergentes. Revista Brasileira de Estudos Urbanos e Regionais. N.1, p.115-132, 1999

VAINER, Carlos B. Pátria, Empresa e Mercadoria. Notas sobre a estratégia discursiva do planejamento estratégico urbano. mar. 1999. p.75-103.

Os liberais também fazem planejamento urbano? Glossas ao "Plano Estratégico da Cidade do Rio de Janeiro". In: Proposta, Rio de Janeiro, n. 69, p. 28-34, jun. 1996.

Pátria, empresa e mercadoria. Notas sobre a estratégia discursiva do Planejamento Estratégico Urbano. In: ARANTES, Otília; VAINER, Carlos \& MARICATO, Ermínia. A cidade do Pensamento único. Editora Vozes, 2002a.

et al. 0 Plano Popular da Vila Autódromo, uma experiência de planejamento conflitual. In: Anais do Encontro Nacional do ANPUR, v. 15, p. 1-18, 2013.

Vitor Fraga da Cunha

Graduando em Filosofia pela UFF. Graduando em Direito pela UNESA. Bolsista PIBIC/UNESA.

\section{Eleonora Freire Bourdette Ferreira}

Professora Adjunta II da Universidade Estácio de Sá. Mestra em Direito pela PUC-RJ. 